\title{
An association between left axis deviation and an aneurysmal defect in children with a perimembranous ventricular septal defect
}

\author{
Odette Farrú-Albohaire, Ghislaine Arcil, Ignacio Hernández
}

\begin{abstract}
Conspicuous left axis deviation was found in two thirds ( 27 patients) of 44 children with a perimembranous ventricular septal defect, echocardiographic signs of apposition of the septal tricuspid valve leaflet, and an aneurysm of the membranous septum. In 10 patients earlier electrocardiograms did not show left axis deviation; this feature appeared when the aneurysm of the membranous septum was first seen on the echocardiogram. None of the 44 controls with perimembranous ventricular septal defect but without an aneurysm had left axis deviation.

This study suggests that the appearances of conspicuous left axis deviation in a patient with ventricular septal defect indicate a spontaneous reduction in the defect by apposition of the septal tricuspid valve leaflet and by the formation of an aneurysm of the membranous septum.
\end{abstract}

Extreme left axis electrocardiographic deviation is uncommon in children and is generally associated with complex congenital heart disease. We noticed that children with an isolated perimembranous ventricular septal defect and echocardiographic signs of a reduction in the size of the defect by the apposition of the septal tricuspid valve leaflet and the formation of an aneurysm often also had left axis deviation.

\section{Patients and methods}

We studied 44 patients, chosen at random, in whom cross sectional echocardiography showed a perimembranous ventricular septal defect that was partially closed by apposition of the septal tricuspid valve leaflet and an aneurysm of the membranous septum. We also studied 44 patients in whom cross sectional echocardiography showed a small to moderate perimembranous ventricular septal defect without apposition of the septal tricuspid valve leaflet or an aneurysm. They too were also chosen at random from those in whom echocardiography showed the relevant signs. We excluded patients with Down's syndrome or any other syndromes and children with other associated congenital heart diseases.

All three of us analysed the standard electrocardiograms of the 88 patients by calculating the QRS axis in the frontal plane and other characteristics of the tracings. We used Student's $t$ test and the $\chi^{2}$ test for statistical analysis. A QRS axis $>-30^{\circ}$ was regarded as left axis deviation. ${ }^{1}$

\section{Results}

The mean age of patients with an aneurysm of the membranous septum was 3 years (range 1 month to 15 years) and in those without it was 2 years (range 1 month to 15 years). The table summarises the electrocardiographic findings in both study groups. Twenty seven $(61 \%)$ of the 44 patients with an aneurysm of the membranous septum had conspicuous left axis deviation (fig 1 ). In the remaining 17 patients the $Q R S$ axis was more positive than $0^{\circ}$ (mean $\left.+60.5^{\circ}\right)$. None of the patients without an aneurysm of the membranous septum had left axis deviation. This difference was highly significant by both statistical tests: $\mathbf{t}=15 \cdot 28$, $\mathrm{p}<0.001 ; \chi^{2}=40.25, \mathrm{p}<0.001$. The mean age at which the left axis deviation appeared or was detected in the 27 children with an aneurysm of the membranous septum was 2 years $-70 \%$ were $<2$ years old, and $50 \%$ were $<7$ months old. Most of the patients in both study groups did not show electrocardiographic evidence of ventricular enlargement; a few showed slight to moderate left ventricular or biventricular enlargement.

Fifteen $(34 \%)$ of the 44 patients with an aneurysm of the membranous septum had an incomplete right bundle branch block compared with only three $(7 \%)$ patients from the group without an aneurysm: $\chi^{2}=10 \cdot 6$, $\mathrm{p} \approx 0.001$. Thirteen of the 27 patients with left axis deviation also had an associated right bundle branch block (fig 2). So half those with a left axis deviation also had a right bundle branch block.

In 10 of the 27 patients with left axis deviation (fig 3A) earlier electrocardiograms had not shown this feature. The appearance of this extreme left axis deviation coincided with clinical evidence that the defect had become smaller and echocardiographic demonstration of apposition of the septal tricuspid valve leaflet and an aneurysm of the membranous septum (fig 3B). (In five of the 10 patients left axis deviation and right bundle branch block occurred simultaneously.) The remaining 17 patients had left axis deviation at presentation.

Only seven patients with an aneurysm of the membranous septum were studied by

Department of del Rio Hospital, Service of Chile G Arcil

Correspondence to Dr Odette Farrú-Albohaire, Accepted for publication
} 
Electrocardiographic findings in patients with ventricular septal defect

\begin{tabular}{|c|c|c|c|c|c|}
\hline & & \multicolumn{2}{|c|}{ With AMS (44) n (\%) } & \multicolumn{2}{|c|}{ Without AMS (44) n (\%) } \\
\hline \multicolumn{2}{|c|}{$\begin{array}{l}\text { QRS axis: } \\
-30^{\circ} \text { to }-90^{\circ} \\
\text { More positive than } 0^{\circ} \\
\text { Mean }\end{array}$} & $\begin{aligned} & 27 \\
& 17 \\
&+ 60 \cdot 5\end{aligned}$ & $\begin{array}{l}(61 \cdot 4) \\
(38 \cdot 6)\end{array}$ & $\begin{array}{r}0 \\
44 \\
+71 \cdot 3\end{array}$ & $\left(0^{\star}\right)^{\star}$ \\
\hline $\begin{array}{l}\text { Chamber enlarg } \\
\text { None } \\
\text { Slight } \\
\text { Moderate } \\
\text { Considerable } \\
\text { Biventricular }\end{array}$ & $\begin{array}{l}\text { LVE } \\
\text { LVE } \\
\text { LVE }\end{array}$ & $\begin{array}{r}25 \\
11 \\
2 \\
0 \\
6\end{array}$ & $\begin{array}{l}(56 \cdot 8) \\
(25.0) \\
(4 \cdot 6) \\
(0) \\
(13 \cdot 6)\end{array}$ & $\begin{array}{r}26 \\
9 \\
3 \\
1 \\
5\end{array}$ & $\begin{array}{r}(59.0) \\
(20.5) \\
(6.8) \\
(2.3) \\
(11.4)\end{array}$ \\
\hline \multicolumn{2}{|c|}{$\begin{array}{l}\text { Incomplete RBBB } \\
\text { Left axis deviation and incomplete } \\
\text { RBBB }\end{array}$} & $\begin{array}{l}15 \\
13\end{array}$ & $\begin{array}{l}(34 \cdot 0) \\
(48 \cdot 0)\end{array}$ & $\begin{array}{l}3 \\
0\end{array}$ & $\begin{array}{l}(6 \cdot 8) \dagger \\
(0)\end{array}$ \\
\hline
\end{tabular}

${ }^{\star} \mathrm{p}<0.001 .+\mathrm{p} \approx 0.001$.

AMS, aneurysm of the membranous septum; RBBB, right bundle branch block; LVE, left ventricular enlargement.

Figure 1 Cross sectional echocardiogram (apical four chamber view) and electrocardiogram showing perimembranous ventricular septal defect and aneurysm of the membranous septum. The electrocardiogram shows left axis deviation. $R V$, right ventricle; $L V$, left ventricle; $R A$, right atrium; $L A$, left atrium.

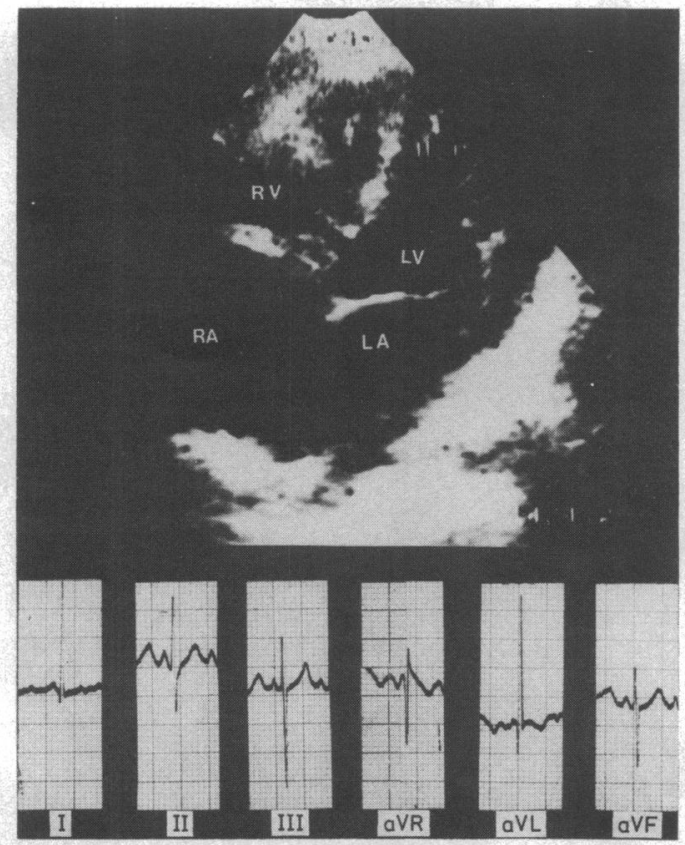

Figure 2 Cross sectional echocardiogram (apical four chamber view) and electrocardiogram showing ventricular septal defect and aneurysm of the membranous septum (arrow). The

electrocardiogram shows left axis deviation and incomplete right bundle branch block. $R V$, right ventricle; $L V$, left ventricle; $R A$, right atrium; $L A$, left atrium $A D$, aneurysmal defect. cross sectional and Doppler echocardiography and all of them had slight to moderate tricuspid insufficiency (fig 4).

\section{Discussion}

Spontaneous closure of membranous ventricular septal defects was reported in between 25 and $80 \%$ of patients. ${ }^{2-4}$ Apposition of the septal tricuspid valve leaflet and an aneurysm of the membranous septum have been suggested as important mechanisms reducing the size of the ventricular septal defect. ${ }^{56}$ In 1957 Steinberg showed angiocardiographically that apposition of the septal tricuspid valve leaflet and an aneurysm of the membranous septum may be related to the spontaneous closure of the ventricular septal defect. ${ }^{7}$ Since then many reports have indicated that the development of an aneurysm of the membranous septum is not only a common and benign finding in patients with ventricular septal defect but also that its appearance usually predicts a reduction in or even spontaneous closure of the ventricular septal defect. ${ }^{689}$ Such features are common in patients with small ventricular septal defects. In the study on the course of aneurysms of the membranous septum by Freedom et al, $70 \%$ of the patients with small ventricular septal defect, who had a pulmonary-to-systemic blood flow ratio of $<2$, had an aneurysm of the membranous septum. ${ }^{6}$ Nugent et al studied 119 patients with ventricular septal defects and found an aneurysm at angiography in $41 \%$ of them at 5.6 years of age and in $61 \%$ at 11 years of age. ${ }^{10}$

Beerman et al found that $45 \%$ of 87 patients with ventricular septal defect and an aneurysm of the membranous septum improved after a median follow up of 8.6 years (range 1.2-18.8). Only $5 \%$ had spontaneous closure of the defect. ${ }^{9}$

The only documented mode of closure of the more common defects of the membranous septum is the adherence of the medial leaflet of the tricuspid valve to the defect. ${ }^{11-13}$

Bäckman studied the QRS axis in 179 patients with ventricular septal defect. He found that the average QRS axis was $+58.0^{\circ}$; $10.1 \%$ of them had an obvious or extreme axis deviation, $>-30^{\circ} .{ }^{1}$ Extreme left axis deviation was found in $1.4 \%$ of healthy infants and children. ${ }^{14}$

Bäckman pointed out that left axis deviation was more common when the ventricular septal defect lay beneath the septal leaflet of the tricuspid valve. Nevertheless, he concluded that it is not possible to establish the site of the defect by electrocardiographic recording.

In our series the association between left electrical axis deviation and a ventricular septal defect beneath the septal leaflet of the tricuspid valve was clearly due not only to the anatomical site of the defect but also to the adherence of the septal tricuspid valve leaflet which reduced the size of the ventricular septal defect. This suggestion is supported by the fact that extreme left axis deviation was a new finding in $\mathbf{1 0}$ of the 27 patients.

It is evident that chamber enlargement can 


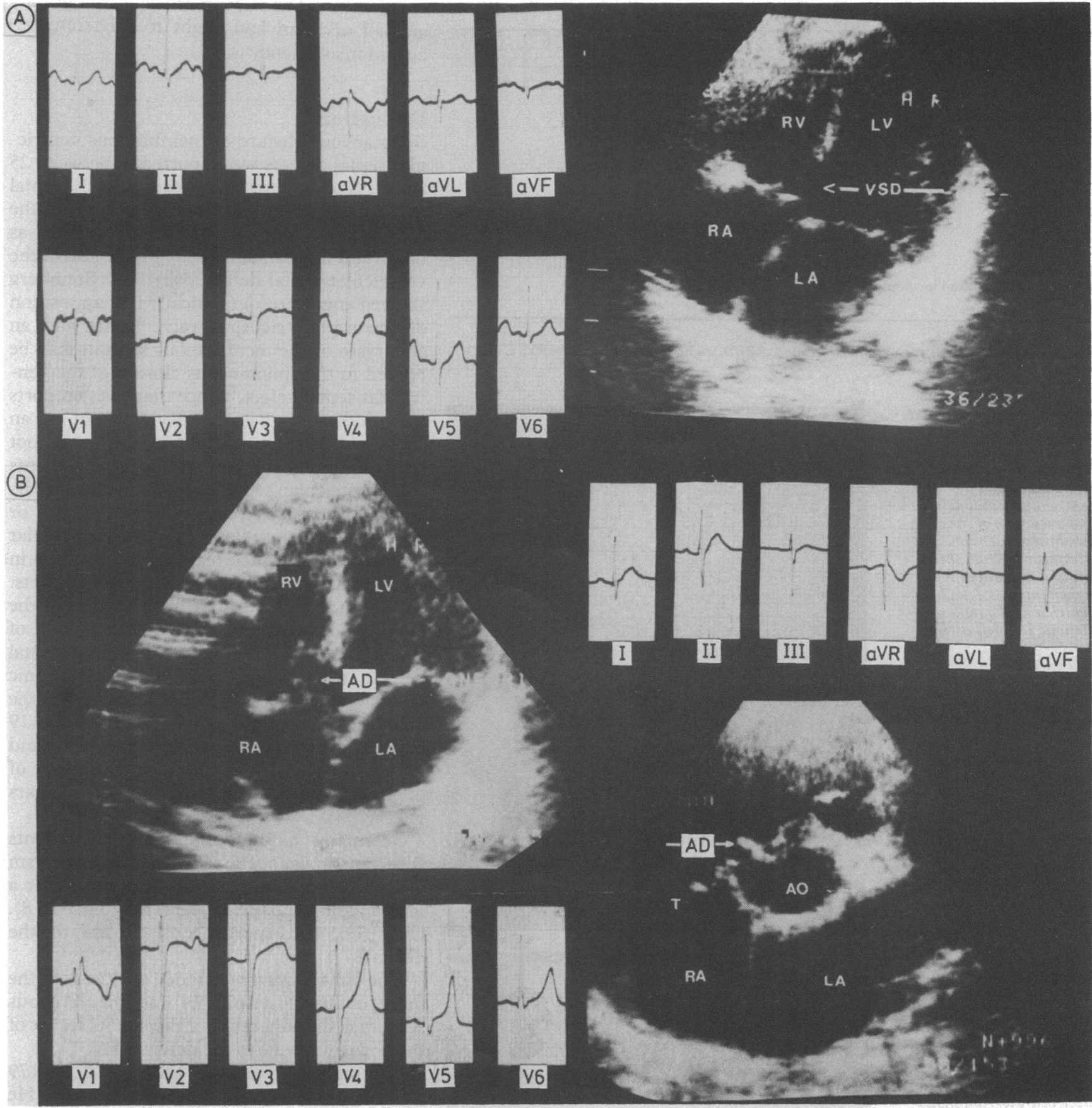

Figure 3 Cross sectional echocardiogram and electrocardiogram. (A) When the patient was three months old the echocardiogram (four chamber view) showed a small to moderate perimembranous ventricular septal defect (arrow) without an aneurysm of the membranous septum. There was no left axis deviation or right bundle branch block on the electrocardiogram. (B) When the patient was five years old the echocardiogram (four chamber view and short axis) showed an aneurysmal defect (arrow) and the electrocardiogram left axis deviation and a right bundle branch block. $R V$, right ventricle; $L V$, left ventricle; $R A$, right atrium; $L A$, left atrium; $V S D$, ventricular septal defect; $A D$, aneurysmal defect; $A O$, aorta; $T$, tricuspid valve.

significantly influence the QRS axis. But the extreme left $Q R S$ axis deviation in our patients cannot be attributed to a great left ventricular enlargement because most of these patients had normal electrocardiograms and few showed only a slight or moderate left ventricular enlargement. Also one of our patients had banding of the pulmonary artery in infancy because of a large ventricular septal defect and heart failure. Some years later angiography showed spontaneous closure of the ventricular septal defect (fig 5) with an aneurysm of the membranous septum and systemic pressure in the right ventricle. The electrocardiogram showed right ventricular hypertrophy and left axis deviation.

Since the case described by Laennec in 1826 , (cited by Freedom et $a l^{6}$ ), there have been many reports of aneurysms of the membranous septum, ${ }^{15-17}$ and the association with many congenital cardiac anomalies, arrhythmias, ${ }^{18-20}$ and conduction defects has been established. ${ }^{182021}$ But an association with an extreme left axis deviation has not been mentioned.

Freedom et al did not find features in the electrocardiogram that distinguished between ventricular septal defect with an associated aneurysm of the membranous septum (seen 
Figure 4 Cross sectional and Doppler echocardiograms in a patient with a

perimembranous

ventricular septal defect, aneurysmal defect and left axis deviation. There was mild to moderate tricuspid insufficiency. $R V$, right ventricle; $L V$, left ventricle; $R A$, right atrium; $L A$, left atrium.

Figure 5 Lateral right ventricular angiogram and electrocardiogram showing the aneurysmal pouch protruding into the left ventricle without shunting (solid arrow)-contrast medium did not enter the left ventricle-and tight banding of the pulmonary artery (open arrow). The electrocardiogram showed left axis deviation and right ventricular overload.
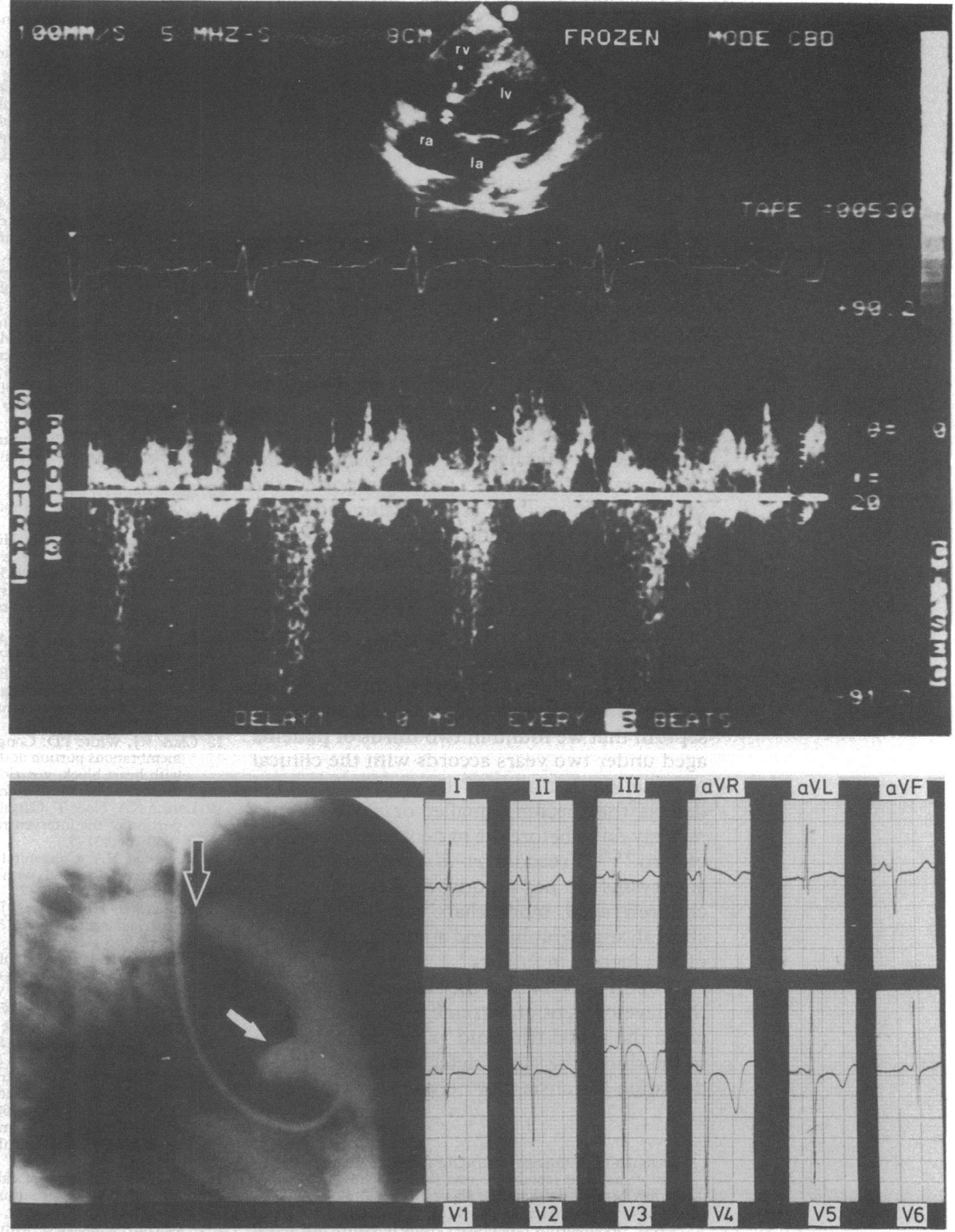

angiocardiographically) and an isolated membranous defect. Only four $(7 \%)$ of their 56 patients had a frontal plane axis of $-15^{\circ}$ to $-60^{\circ}$; two of them had an aneurysm. ${ }^{6}$

So far angiocardiography has been the only means of diagnosing aneurysms of the membranous septum. ${ }^{610}$ But patients with small ventricular septal defect do not generally need angiocardiography and should be managed clinically. The incidence of such aneurysms of the membranous septum is therefore unknown, though it was thought to be high. 6910

Today the non-invasive technique of echocardiography can easily confirm the presence of aneurysms of the membranous septum associated with perimembranous ventricuar septal defects and follow them through the years. $^{22-24}$ We found that the short axis and apical four chamber views were the most helpful in visualising the area of the membranous septum. An aneurysm of the membranous septum is often found at echocardiography ${ }^{24}$ in patients with a perimembranous ventricular septal defect but the high frequency of an extreme deviation of the left axis in our patients is surprising. We believe that spontaneous closure of ventricular septal defect can be anticipated if the defect becomes smaller and a left axis deviation appears.

We think that far from being an indication for invasive studies the development of left axis deviation in patients with small ventricular septal defects forecasts the spontaneous reduction of the defect by apposition of the septal tricuspid valve leaflet and by an aneurysm of the membranous septum. Such patients only 
need careful clinical management even if the venticular septal defect is large and seems to need surgical closure.

Bäckman found that $7 \cdot 8 \%$ of his patients with left axis deviation also had incomplete right bundle branch block. ${ }^{1}$ We found that half of our patients with left axis deviation also had right bundle branch block.

There have been several reviews of the anatomical relation of aneurysms of the membranous septum to the tricuspid valve. ${ }^{131525}$ They suggested that dysfunction of the tricuspid valve was likely because it was affected by the aneurysm of the membranous septum. Freedom et al reported angiographc evidence of tricuspid insufficiency in four patients with aneurysms of membranous septum. They also suggested that an aneurysm can cause tricuspid insufficiency, perhaps by deforming the overlying septal leaflet. ${ }^{6}$ Others reported the same association. ${ }^{172627}$ This dysfunction may explain the tricuspid insufficiency found in all seven patients that we studied by Doppler echocardiography.

At auscultation tricuspid valve dysfunction may be masked by the features of the associated ventricular septal defect.

The apposition of the septal tricuspid valve leaflet and the aneurysm of the membranous septum that we found in two thirds of patients aged under two years accords with the clinical observation that most of the ventricular septal defects that become smaller or close spontaneously do so before the patient reaches the age of two. ${ }^{3628}$ Freedom et al pointed out that aneurysms are not unique, as was thought, to children aged more than two; they found clinical, angiographic, and anatomical evidence of this feature in infants. ${ }^{6}$

We still do not know the anatomical basis for the development of extreme left axis deviation when the septal tricuspid valve leaflet adheres to the rim of the septal defect and whether this deviation is transient or permanent.

1 Bäckman $\mathrm{H}$. Influence of structural and functional features of ventricular septal defect on frontal plane QRS axis of the electrocardiogram. Br Heart J 1972;34:274-83.

2 Agustsson MH, Arcilla RA, Bicoff JP, Moncada R, Gasul BM. Spontaneous functional closure of ventricular septal defects in fourteen children demonstrated by serial cardiac catheterizations and angiocardiography. Pediatrics 1963; 31:958-68.
3 Hoffman JIE, Rudolph AM. The natural history of ventricular septal defect in infancy. Am J Cardiol 1965; 16:634-53.

4 Campbell M. Natural history of ventricular septal defect. $\mathrm{Br}$ Heart J 1971;33:246-57.

5 Varghese PJ, Izukawa T, Celermajer J, Simon A, Rowe RD. Aneurysm of the membranous ventricular septum: a method of spontaneous closure of small ventricular septal defect. Am J Cardiol 1969;24:531-6.

6 Freedom RM, White RD, Pieroni DR, Varghese PJ, Krovetz LJ, Rowe RD. The natural history of the socalled aneurysm of the membranous ventricular septa defect. Circulation 1974;49:375-84.

7 Steinberg I. Diagnosis of congenital aneurysm of the ven tricular septum during life. Br Heart $J$ 1957;19:8-12.

8 Edelstein J, Charms BL. Ventricular septal aneurysm. Circulation 1965;32:981-4.

9 Beerman LB, Park SC, Fisher DR, et al. Ventricular septa defect associated with aneurysm of the membranous septum. J Am Coll Cardiol 1985;5:118-23.

10 Nugent EW, Freedom RM, Rowe RD, Wagner HR, Rees $\mathrm{JK}$. Aneurysm of the membranous septum in ventricular septal defect. Circulation 1977;56(suppl I):82-4.

11 Albers HJ, Carroll SE, Coles JC. Spontaneous closure of a membranous ventricular septal defect. Br Med J 1962; iil: $1162-3$.

12 Bloomfield DK. The natural history of ventricular septa defect in patients surviving infancy. Circulation 1964 29:914-55.

13 Anderson RH, Lenox CC, Züberbühler JR. Mechanism of closure of perimembranous ventricular septal defect. $A m$ Cardiol 1983;52:341-5.

14 Gup AM, Franklin RB, Hill JE. The vectorcardiogram in children with left axis deviation and no apparent hear disease. Am Heart $J$ 1965;69:619-23.

15 Baron MG, Wolf BS, Grishman A, Van Mierop LHS Aneurysm of the membranous septum. Am J Roentgenol 1964;91:1303-14.

16 Jain AC, Rosenthal R. Aneurysm of the membranous ventricular septum. Br Heart J 1967;29:60-3.

17 Chesler E, Korns ME, Edwards JE. Anomalies of the tricuspid valve, including pouches, resembling aneurysms tricuspid valve, including pouches, resembling aneurysms 1968;21:661-8.

18 Clark RJ, White PD. Congenital aneurysmal defect of the membranous portion of the ventricular septum associated with heart block, ventricular flutter, Adams-Stokes syndrome and death. Circulation 1952;5:725-9.

19 Larsen KA, Noer T. Cardiac aneurysm of the membranou portion of the interventricular septum. Acta Med Scand 1960;166:401-5.

20 Heggtveit HA. Congenital aneurysm of the membranous septum associated with bundle branch block. Am Cardiol 1964;14:112-7.

21 Shumacker HB, Glover J. Congenital aneurysm of the ventricular septum. Am Heart J 1963;66:405-8.

22 Snider AR, Silverman NH, Schiller NB, Ports TA. Echocardiographic evaluation of ventricular septal aneurysms. Circulation 1979;59:920-6.

23 Canale JM Sahn DJ, Valdes-Cruz LM, Allen HD Goldbers SJ, Ovitt TW. Accuracy of two-dimensional Goldberg SJ, Ovitt TW. Accuracy of two-dimensional echocardiography in the detection of aneurysms

24 Ramaciotti C, Keren A, Silverman NH. Importance of (perimembranous) ventricular septal aneurysm in the natural history of isolated perimembranous septel defect. Am J Cardiol 1986;57:268-72.

25 Tandom R, Edwards JE. Aneurysmlike formation in relatio to membranous ventricular septum. Circulation 1973;47: 1089-97.

26 Pombo E, Pilapil VR, Lehan PH. Aneurysm of the mem branous ventricular septum. Am Heart J 1970;79:188-93.

27 Eshaghpour E, Kawai N, Linhart JW. Tricuspid insufficiency associated with aneurysm of the ventricula feptum. Pediatrics 1978;61:586-92.

28 Hoffman JIE, Rudolph AM. The natural history of isolated ventricular septal defect. Adv Pediatr 1970;17:57-79. 